\title{
De la racionalidad a la credibilidad: La propuesta epistemológica hacia la fe en la Gramática del asentimiento de John Henry Newman
}

\author{
Luis MAURicio AlbornOz OLIVARES* \\ Universidad Católica del Maule (Chile) \\ malborno@ucm.cl
}

\begin{abstract}
Resumen
A partir de la Ilustración, la ciencia y la $f e$-otrora caminos comunes para alcanzar conocimiento-, se han visto divorciadas y constituidas como realidades divergentes que se oponen cada vez más. La modernidad trajo consigo la insistencia en estas ideas y el divorcio entre ciencia y fe parece no detenerse. El presente artículo propone en un dialogo con John Henry Newman reconocer el lugar propio de la ciencia positiva respecto de la fe religiosa, presentando la distinción epistemológica, o el modo de comprender el conocimiento que hace de la fe un camino plausible y posible que tiene su propia estructura epistémica dirigida hacia la credibilidad de la fe religiosa.
\end{abstract}

Palabras claves: Newman, ciencia, fe, conocimiento, epistemología.

\section{From rationality to credibility: \\ The proposal to epistemological faith in the "Grammar of assent" by John Henry Newman}

Abstract

Since the Enlightenment, science and faith - once common ways to achieve knowledge - have been divorced and incorporated as divergent realities that increasingly oppose. Modernity brought with it the insistence on these ideas and the divorce of science and faith does not seem to stop. The present article proposes in a dialogue with John Henry Newman to recognize the proper place of positive science regarding religious faith, presenting the epistemological distinction, or the way of understanding the knowledge that makes of faith a plausible and possible path that has its Own epistemic structure directed towards the credibility of religious faith.

Key words: Newman, science, faith, knowledge, epistemology.

Doctor en Teología Dogmática por la Pontificia Universidad de Salamanca, y actualmente Decano de la Facultad de Ciencias Religiosas de la Universidad Católica del Maule. Ha publicado "¿Cómo creer hoy en Dios? elementos para una introducción a la fe cristiana" (2008); "La fe como interpretación de la cultura" (2012); "John Henry Newman y la condición antropológica como fundamento para la teología de la credibilidad" (2015); "Ciencia positiva y fe religiosa: caminos hacia el conocimiento" (2016). 


\section{INTRODUCCIÓN: EL DECIR EPISTEMOLÓGICO}

En términos simples la epistemología busca dar una explicación o interpretación filosófica al modo en que se desarrolla el conocimiento humano ${ }^{1}$. Específicamente se ubica el decir epistemológico en la estructura interior del acto de conocer, descubriendo los modos, límites y alcances a través de los cuales el conocimiento llega a producirse y consolidarse (Ferrater Mora, 2004; Pooper, 1974). En términos lógicos se afirma que el problema radica, no en conocer que $N$, sino en conocer cómo se conoce que $N$. Se trata de asumir que el entendimiento posibilita un acceso a la verdad del conocimiento que, aunque no pueda estar exento de potenciales errores, carecería de sentido de no tener acceso a ella, "pues un entendimiento incapaz de captar la verdad no saldría del error por más vueltas que a éste le diera" (Llano, 1983: 20)².

Este conocimiento puede ser verdadero tanto en su proposición, y en este caso se dice que la proposición es verdadera a diferencia de la falsa, como para referirse a una realidad en donde se habla de realidad verdadera a diferencia de una aparente o inexistente. En esta distinción emerge un concepto de verdad discutido históricamente de acuerdo a las relaciones de las verdades de hecho o de razón ${ }^{3}$. Se opta aquí por una gradación entre las verdades de hecho y de razón, según lo cual toda proposición puede ser verdad de hecho y de razón (Ferrater Mora, 2004).

Ahora bien, si se sigue la concepción más extendida de la verdad con la adecuación del intelecto a la cosa, la verdad sería una propiedad del intelecto que al juzgar se conforma a la realidad. Este camino no resulta complejo en este estudio, pues apunta al seguimiento que se va haciendo. Incluso las

1 Etimológicamente significa estudio del conocimiento, o estudio de la ciencia, y puede entenderse como la rama de la filosofía que estudia los problemas del conocimiento (Ferrater Mora, 2004; Russell, 1978). En una buena síntesis se puede consultar a Copleston (1969). Ernst Cassirer (2000) se inscribe en esta misma perspectiva, su reinterpretación de Kant consiste en hacer de la actividad cognoscitiva del espíritu humano, que se realiza a través de formas (espacio y tiempo y categorías), una parte de la actividad simbólica más general del espíritu que posee la capacidad de representarse simbólicamente —esto es, de referir a un significado espiritual-, los datos de la experiencia.

2 Esta posibilidad es la misma que en el santo de Hipona se expresa con objetividad: "Confiesa que tú no eres la verdad, pues ella no se busca a sí misma, mientras tú le diste alcance por la investigación, no recorriendo espacios, sino con el afecto espiritual, a fin de que el hombre interior concuerde con su huésped. [...] Tales verdades no son producto del raciocinio, sino hallazgo suyo. Luego antes de ser halladas permanecen en sí mismas." (De Hipona, 1979:18-19). En cualquier caso, alcanzar la verdad, y en este caso en relación al conocimiento, se afirma como camino posible.

3 Para profundizar en esta distinción puede ser útil el texto de Heidegger, De la esencia de la verdad (2007). 
críticas que han surgido a estas comprensiones de verdad resultan favorecedoras a esta investigación, pues inquieta, no la adecuación del intelecto, sino el tipo de adecuación y el establecimiento de tal o cual adecuación, por tanto, la significación última de verdad no queda entrampada, en este caso, en las disquisiciones que frente a ella se puedan tener (Tejedor, 1984).

Se trata entonces de la posibilidad y definición del conocimiento en su proceso propedéutico, donde se entremezclan diversas fuentes y grados de certeza que lo harán posible. $N$ cree que $R$, si, y sólo si, es verdad que $R$; es decir, $N$ sabe que $R$ si está justificado el creer que $R^{4}$.

Este modo de entender el problema, no resulta baladí, pues a través de estas afirmaciones previas se observa una asimilación del problema del conocimiento que se encuentra tensionado con la discusión epistemológica hoy, lo que trae como consecuencia una minusvaloración de los antecedentes propios que eventualmente pueden justificar la fe religiosa o desvirtuarla, según la aplicación epistemológica sugerida. Desde otra perspectiva una reductiva comprensión epistemológica puede conducir a una visión restrictiva de la credibilidad de la fe, afectando entrañablemente su plausibilidad y por ende su comprensión y su teología. Esta es la advertencia que realiza Antón al hablar de la recepción epistemológica del Concilio Vaticano II que ha hecho G. Routhier explicitando que en una sana epistemología teológica: "no caben opciones monistas entre doctrina y práctica o entre procesos deductivos e inductivos. Ambos aspectos deben entrar en la metodología teológica del fenómeno de la recepción y acentuar uno no debe llevar a minusvalorar el otro" (Antón, 1996: 57-96). La reflexión epistemológica no puede prescindir del análisis inductivo y este ha de realizarse siempre desde los principios del conocimiento teológico.

Esta es la razón por la que se hace necesario poner de relieve la discusión y examinar las consecuencias que determinada epistemología puede acarrear. En efecto, el problema se presenta complejo desde su definición ulterior, pues hablamos de los fundamentos del saber teológico. En este sentido la epistemología en teología busca proporcionar las fuentes de credibilidad de la fe. Esta cuestión fue en su momento sugerida por Melchor Cano (1509-1560) en el De locis theologicis y profundizada en el devenir del tiempo por autores como T. Stapleton en su Principiorum fidei doctrinalium

\footnotetext{
4 Conocer aquí, es creer algo porque se sabe que se puede demostrar con una argumentación concluyente (Toulmin, 1976). Conocer, en este caso, consiste en saber que un enunciado es verdadero. Esta clave de profundización epistemológica es la que sigue Cassirer (2000), que en el segundo volumen de su obra da una amplia cobertura al problema epistemológico en el empirismo inglés. Autores como Francis Bacon (1561-1626), Thomas Hobbes (1588-1679), John Locke (1632-1704), George Berkeley (1685-1753) y David Hume (1711-1776) son solicitados en este manual que posibilita seguir de modo progresivo el problema del conocimiento.
} 
demonstratio metodica. De igual modo en M. J. Scheeben en su Dogmática: Theologische Erkenntnislehre, lo que derivó en su inserción en la demonstratio catholica como lugar epistemológico.

En cualquier caso, como recuerda Fisichella (1993) la teología solicita una justificación de sus pretensiones científicas, lo que deriva en una epistemología adecuada, esto por la propia naturaleza del saber que necesita ser comunicable y universalmente transmisible, lo que exige a su vez, de su cientificidad considerando positivamente todas sus variables (Congar, 1970; Kérn \& Niemann, 1986; Lonergan, 1988; Pannenberg, 1981). Así el valor de la epistemología tendrá como objetivo final la justificación del carácter científico de la globalidad de la teología que, en cuanto ciencia de la fe, buscará en la epistemología la función primaria de sus pretensiones científicas y el referente necesario para la investigación. Esto hace que la fe vivida y profesada tenga plausibilidad y en consecuencia credibilidad.

Ahora bien, Newman no intenta elaborar una epistemología propia o sistemáticamente desarrollada, el problema para él es la fe religiosa y el modo en que se llega a ella a través de un tipo de conocimiento no necesariamente científico, su preocupación es la fe religiosa no la epistemología, no obstante, este desarrollo se encuentre implícito casi a nivel psicológico en la descripción que nuestro autor formula. Esta es la visión de autores como Morado (2000) que coincide en decir que la intención primordial de Newman es la justificación del asentimiento a la fe, y en consecuencia tomar distancia frente al empirismo de corte racionalista tan recurrente en los tiempos de Newman como en el presente. Asimismo, Juan Morado difiere de Dessain (1960) que se mantiene en la idea más radical en donde, según su percepción, Newman no aborda el problema epistemológico en cuanto tal, y la impronta newmaniana se circunscribe en el ámbito psicológico más que epistémico ${ }^{5}$.

En cualquier caso, el punto está en que el problema del conocimiento exige la profundización de nuestro autor, y en consecuencia una visión epistemológica resulta ineludible en él. Así el decir epistemológico de Newman se transforma en necesidad ineludible y cuyo carácter reviste en

\footnotetext{
5 Es necesario dejar claro que a Newman no le interesa, en principio, dar cuenta del quehacer epistemológico o de plantear una epistemología propia. Newman llega al problema del conocimiento en virtud de la fe y la tensión racionalista que a ella se le imponía. Pero, hay que reconocer que el esfuerzo de Newman para justificar el asentimiento a la fe del hombre corriente implica una visión necesariamente epistemológica, como se demostrará, cuestión que no renuncia a lo psicológico, como señala Rutler "El propósito de Newman no es menos psicológico que epistemológico, y parte de su proyecto es eliminar todo falso hiato entre ambos campos" (Rutler, 1990: 745-755). Así Newman amplia la visión epistemológica, y por tanto, el conocimiento humano frente a restricciones estrictamente racionalistas y positivistas (Morado, 2000).
} 
el oxoniense un itinerario existencial autobiográfico como destaca Dalibor Renic (2015). Una experiencia religiosa que fuese fruto de una deducción silogística no tendría espacio en el ser y decir newmaniano, por lo que hoy como ayer la comprensión epistemológica de la creencia y su consecuente teológico, resulta de particular necesidad para no exigirle a la fe aquello que por naturaleza ella no nos puede dar.

Newman va a proponer esclarecer en su obra titulada An Essay an Aid of a Grammar of Assent del año 1870 el proceso del conocimiento, constituyéndolo como aproximación frente a aquello que se entiende es la epistemología (Newman, 1992). Todo en la perspectiva de buscar dar a conocer y fundamentar, el natural camino racional epistemológico que posibilita la credibilidad de la fe religiosa.

\subsection{Conocimiento y verdad}

Epistemológicamente hablando, la verdad se puede afirmar en cuanto da fiabilidad al modo a través del cual se alcanza ésta. Es decir, no se está en la búsqueda de la verdad en cuanto al objeto que puede o no ser verdadero, sino a que la forma a través de la cual se llega a la certeza de lo verdadero sea a su vez legítimamente verdadera. De este modo la verdad se erige en clave de estudio no como un fin en sí misma, sino como medio que justifique el fin, y al justificar el fin se justifica ella misma. En este contexto la ciencia, propiamente hablando, presenta un modo de conocer el mundo, y a su vez propone un determinado cuerpo de conocimiento. Las preguntas epistemológicas son en sí mismas un modo de conocimiento, como asimismo un cierto cuerpo de presuntos conocimientos. Esto es lo más característico del conocimiento científico (Copleston, 1969).

Así las cosas, el problema epistemológico se caracteriza como búsqueda de la verdad, presentándose estructuralmente como un cuerpo de acumulación de verdades o presuntas verdades, que tal búsqueda o investigación haya originado. Surgen ahora una serie de preguntas básicas referente al status de dichos conocimientos y presunciones de conocimiento: ¿qué quiere decir que la persona sabe o que tiene razones para creer esto o aquello? ¿Por qué medios adquiere dicho conocimiento? ¿Qué diferencia hay entre las conjeturas e hipótesis iniciales y aquellas que se dan por confirmadas? ¿Qué papel desempeña la percepción sensorial en la adquisición de conocimientos? ¿Qué relación guarda el pensamiento con dicha percepción? ¿Qué papel desempeña la deducción en la génesis de presuntos conocimientos?, en una alternativa entre presuntos conocimientos que 
sean incompatibles, ¿Cómo se elige? y ¿Qué sirve para garantizar o justificar las creencias, por una parte y, por otra, para desecharlas o combatirlas? (Wartofsky, 1973).

$\mathrm{El}$ principio fundamental es que para conocer realmente algo, es necesario que ese algo sea verdad. Surge entonces una correlación entre el objeto conocido y la verdad de este objeto conocido, suscitándose razones para creer aquello que es conocido. Evidentemente que estas razones no pueden ser falsas, pues debe haber una correlación entre la verdad del conocimiento alcanzado y las razones que llevan a reconocer esta verdad. Se está aquí ante una concepción clásica del conocimiento que solicita la relación sujeto-objeto como partes constitutivas del acto mismo de conocer, esto, en tres niveles de referencia:

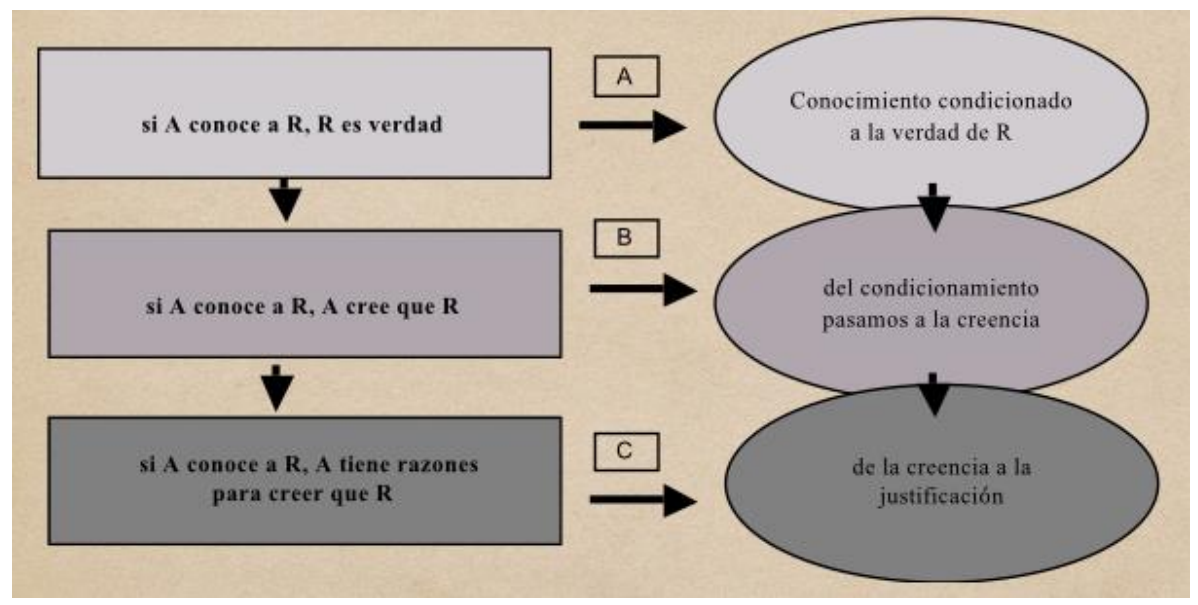

En los dos primeros casos el conocimiento pasa a ser una realidad que acontece en el sujeto, pero esto cambia en $C$ donde si bien el que conoce es el individuo - por tanto, sigue presentándose cierta subjetividad-, al darse las razones del porqué $A$ conoce a $\mathrm{R}$ y las razones de $A$ para creer que $\mathrm{R}$, se podría suponer que aquello que $A$ conoce también podría conocerlo $X$ o $Z$. En este nivel referencial del conocimiento se habla de una realidad objetiva, y en cuanto objetiva el sujeto cognoscente pierde relevancia en el procedimiento epistemológico mismo. En consecuencia, la clave positivista haría más verdadero el conocimiento, dado el carácter científico que le induce. La pregunta que surge en este contexto es saber si existen verdades que, no siendo justificadas bajo categorías lógico-formales de la ciencia, como en el ejemplo recién descrito, pueden efectivamente reconocerse como verdades. 


\subsection{Otra forma de conocimiento}

La teoría epistemológica presentada conlleva a citar el conocimiento científico que podría definirse como aquella creencia racional justificada. El problema se presenta ahora en el carácter de esta justificación así llamada científica. Por ejemplo: Patricio quiere saber si esta noche va a llover. Usando un termómetro puede observar que la temperatura se mantiene, a esto le suma un barómetro que muestra una condición estable de presión atmosférica, además considera un higrómetro que no muestra variaciones en la humedad del aire, Patricio puede finalmente deducir que no lloverá, pues, ninguno de los instrumentos utilizados para las diferentes mediciones acusan indicios de lluvia. Aquí se tiene una justificación científica-instrumental para alcanzar un determinado conocimiento respecto de la situación del clima en esta noche.

Ahora bien, Pedro dice que esta noche no va a llover, y dice que no va a llover porque en esta época del año no llueve, y además porque no hay nubes en el cielo, a ello suma que no corre viento norte y que la humedad del aire no la percibe. Llega la noche y efectivamente no llueve. Entonces Pedro dice, jsabía que no iba a llover! En este ejemplo nadie va a dudar que Pedro efectivamente supiera que no llovería y que además sabía por qué no iba a llover. En conclusión, Pedro tenía cierto conocimiento de que no iba a llover, pues tenía cierto contacto consciente con el objeto conocido y los datos que este objeto conocido solicita para que efectivamente así acontezca. Pero el conocimiento de Pedro no equivale al de Patricio. Sin embargo, ambos llegan a la misma conclusión.

Se podría decir en el ejemplo que Pedro tiene mayor certeza que $\mathrm{Pa}-$ tricio en que no lloverá, pues afianza su postulado en otro tipo de convicciones no instrumentales, ni propiamente científicas, y que se fundan principalmente en su experiencia y sentidos. En todo caso en ambas posibilidades, las conclusiones, dadas las premisas, parecen razonables. Sin embargo, podría darse que las conclusiones fueran diversas entre Patricio y Pedro, y alguno de ellos o ambos hubiesen errado en su análisis, para el caso no interesan las conclusiones, sino el modo en que se llega a ellas. Es decir, hay un tipo de conocimiento diferente en Pedro que no niega el de Patricio, pero claramente hay una distinción epistemológica entre los modos de alcanzar conocimiento más allá de los resultados. En cualquier caso, hay razones que justifican una forma de alcanzar conocimiento en ambos casos que, si bien son fundamentalmente distintas, en términos lógicos no. Ahora, ¿qué pasaría si el objeto de análisis no fuese la lluvia sino la fe religiosa? Surge entonces el problema epistemológico que Newman intenta analizar. 


\section{LA COMPRENSIÓN EPISTEMOLÓGICA DE NEWMAN}

\subsection{El método newmaniano}

Los métodos empiristas que Newman va a presentar le permiten desarrollar una sistemática del rol de la percepción interior ${ }^{6}$, como evidencia histórica del único Dios verdadero que se muestra válido para todo tiempo y lugar. El método newmaniano dice relación directa con lo que de hecho sucede; es la experiencia el punto de partida para su reflexión. Para el oxoniense es claro que la sola razón, por sí misma, no es capaz de dar fuerza suficiente a la toma de decisiones y traducirse, en cuanto razón, en experiencia práctica. Tampoco es capaz de hacer responsable a la persona, sólo por los juicios que deriven de la experiencia, sino que él ve necesario algo más. Ejemplificándolo religiosamente, Newman dirá que "muchos hombres viven y mueren por un dogma; ninguno será mártir por una conclusión" (Newman, 1992: 93). Entonces: ¿qué tipo de comprensión epistemológica se descubre en el autor?

Newman comienza describiendo cómo se da el proceso y ejercicio cognoscente en el ser humano. La primera exigencia que plantea es el correlato natural entre la realidad del objeto y aquello que de el se aprehende. Dicho gramaticalmente, el predicado dará cuenta de aquello que se aprehende del sujeto, pero a su vez, se requiere que lo que el predicado enuncie sea conocido. De este modo la relacionalidad entre sujeto cognoscente y objeto conocido logra ser aprehendida y asentida ${ }^{7}$. Así lo expresa el siguiente esquema:

6 En esto de la percepción interior como modo de conocimiento, Newman resulta reiterativo. A la hora de legitimar la fe, la fuerza primaria no radica en las evidencias externas del cristianismo, como pudiesen ser los milagros y las profecías (el Concilio Vaticano I en su constitución dogmática Dei Filius afirma y describe los signos externos de credibilidad y Pío X en su discurso antimodernista Sacrorum Antistitum daba fianza certísima como signo de credibilidad a estos mismos hechos (Denzinger \& Hunerman, 2002: n. 3002; 3539, y también: 772, 2753, 2754, 2768, 2779, 3033). Newman concede más valor al aspecto personal del razonamiento que conduce a la fe, ya que sin asumir nada no se puede razonar (Fuente Martínez, 1998).

7 Esto va a depender si aquello que se aprehende permite un conocimiento tal que haga posible un asentimiento a él. En esto, basta saber que Newman describe el principio de razón como el camino a través del cual el hombre avanza en su conocimiento. En este sentido, si a partir de lo que se conoce es posible llegar a nuevos conocimientos, la fe no actúa de un modo distinto y puede, por tanto, verse como un ejercicio de razón. (Newman, 2003). 


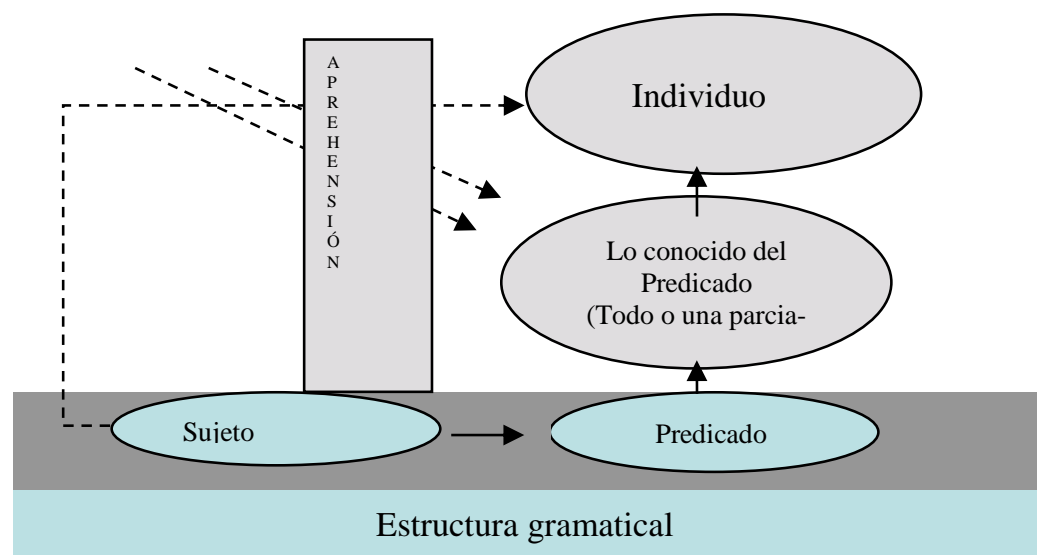

En un ejemplo. Si se afirma la frase: El agua es pura y cristalina, para que exista conocimiento a esta proposición se debe a su vez conocer lo que significa puro y cristalino y haber asentido a ello. Si junto a esta afirmación se muestra al sujeto cognoscente una vertiente de agua en la Patagonia, tanto el asentimiento a la proposición, como el conocimiento de ella, quedan evidenciados en lo conceptual y lo experiencial. No solamente se sabe que el agua es pura y cristalina, sino que también se sabe lo que es puro y cristalino, el predicado de la proposición. Si no hubiese experiencia del agua de todos modos se puede aprehender la afirmación conceptualmente. En cualquier caso, el predicado demuestra una cualidad del sujeto agua, pero esta cualidad requiere a su vez un conocimiento de su significado independiente que exista o no conocimiento del agua a nivel de experiencia, es decir, se puede imaginar que el agua es pura y cristalina solo por el conocimiento del significado puro y cristalino, esto aunque ninguno de los sujetos cognoscentes haya viajado nunca a la Patagonia a conocer sus manantiales.

\subsection{De la formalidad a la credibilidad}

Ahora bien, ¿qué pasaría si se cambia el sujeto agua por $\mathrm{H} 2 \mathrm{O} ?^{8}$. Se afirma: El H2O es pura y cristalina. Con esto se da una aprehensión de la proposición, aunque no se comprenda a cabalidad el significado de la misma. Del agua existe un conocimiento universal y casi natural, no obs-

\footnotetext{
8 Lo que se pretende enfatizar es la experiencia de aquello que se señala con el concepto agua. No se habla del problema lingüístico o idiomático del concepto agua, pues en este sentido decir $\mathrm{H} 2 \mathrm{O}$ es mucho más universal. Se habla aquí del significado no del significante.
} 
tante, hablar del $\mathrm{H} 2 \mathrm{O}$ para referirse al agua puede ser ignorado por el sujeto y por tanto se dificulta la relación cognoscente, aunque conceptualmente se comprenda que aquello que es el $\mathrm{H} 2 \mathrm{O}$ es puro y cristalino. En efecto si se aprehende que el $\mathrm{H} 2 \mathrm{O}$ es puro y cristalino tal aprehensión puede reconocerse como tal y asentir a ella. Pero en este caso el asentimiento a tal afirmación está en un nivel distinto al que se daría si hubiera conocimiento experiencial.

Este tipo de conocimiento que posibilita aprehensión al margen de toda realidad experiencial no es menos conocimiento, sino distinto. No obstante, como señala Torres Queiruga una característica que penetra todo el tratamiento newmaniano de las cuestiones epistemológicas es la atención a los datos concretos que proporciona una experiencia directa y viviente de la realidad, la apertura a la realidad de las cosas y de nosotros mismos, tal como se descubre en la indeducible alteridad. Su problema era la cosa misma (Torres Queiruga, 1991). Aquí radica el problema epistemológico. El conocimiento que se ve favorecido por una determinada experiencia abre paso a una certeza, al menos como posibilidad, que en materia de fe resulta determinante, pues lo que busca la fe religiosa es que se viva, se practique, se traduzca en hechos; no la aprehensión de ciertos silogismos, y esto es lo que Newman intenta formular de tal manera de llevar a la práctica de la fe y no quedarse en la teorización de la misma.

En términos teológico-fundamentales se diría que la cuestión tiene que ver con la fides quae, es decir, aquella realidad que propone contenidos respecto de lo que se cree y que posibilita que haya conocimiento de los mismos. Esto, por supuesto, no significa que no exista fides qua como aceptación total del Dios que se revela, pues no hay separación entre ambas; los dos términos quieren especificar los diversos momentos de un acto único. Al creer, la persona acepta un contenido que la compromete; por tanto, la fides qua no abstrae de la fides quae, sino que está determinada por ella. He ahí la importancia del conocimiento o de aquello que se puede conocer en materia de fe, y el modo a través del cual se conoce. Pues, si la racionalidad permite afirmar un modo de conocer posible y plausible, entonces el contenido de lo que se cree también está sujeto a este modo de conocer para que sea posible y plausible, fundamento de credibilidad. Por lo que la racionalidad lleva a la credibilidad bajo la impronta del conocimiento, al menos como condición de posibilidad, es decir, se exige cierto grado de conocimiento (Aveling, 1905; Cazes, 1960; Chenk, 1986; Chiochetti, 1948; Ker, 1977), pues, "Una noción intelectual no puede competir con los efectos de la experiencia de hechos concretos" (Newman, 1992: 31).Con esta afirmación queda en evidencia que la distinción respecto del problema del conocimiento en Newman tiene un fin práctico, a saber, la vida religiosa concreta, o dicho en su terminología el 
real assent, el asentimiento real a la fe. Por tanto, el ejercicio racional que discurre en el problema del conocimiento, busca favorecer la credibilidad de la experiencia creyente. En esta perspectiva el autor da un paso más al distinguir entre la inferencia y el asentimiento, o parafraseándolo, entre nociones y realidades, en cualquier caso, se busca llegar al asentimiento de la fe.

\subsection{De la imagen al conocimiento}

Con el ejemplo descrito en el punto anterior se puede concluir con Newman que el encuentro dado entre el sujeto y objeto produce la relacionalidad necesaria para que se dé, como condición de posibilidad, tal o cual conocimiento, este último es el correlato natural. En otras palabras, el sujeto toma la condición de tal en virtud de un objeto, y el objeto sólo es objeto para un sujeto. El sujeto aprehende el objeto y el objeto es aprehensible y aprehendido por el sujeto. Así, el verdadero conocimiento expresará en su contenido una total coherencia con el objeto mentado, mediado este por el asentimiento sin el cual no puede haber conocimiento. Para Newman la verdad expresa una relación; la relación del contenido del pensamiento, de la imagen, con el objeto. No se está insistiendo en el objeto en cuanto tal, sino en la imagen de él que es aprehendida y a la cual se asiente. En último término es la imagen la que verdaderamente se conoce.

No hay que olvidar que la epistemología desarrollada por Newman (1908) buscaba la reivindicación del carácter razonable de la fe (logical cogency of faith) cristiana (Fisichella \& Latourelle, 1992). Tal inquietud tiene sus fuentes más directas en el deseo del oxoniense de escribir la Grammar of Assent, como lo afirma en sus Cartas y Diarios: "si escribiera un nuevo trabajo, sería la demostración (evidence) popular, práctica y personal, del cristianismo, en contraste con la científica, y su objeto sería mostrar que un individuo dado, instruido o no, tiene tanto derecho a estar cierto, como un docto teólogo que conoce la demostración científica" (Newman, 1962: 294).

Aquí es importante clarificar que no se busca una justificación objetiva de la fe (fides quae), sino validar la misma en lo cotidiano de las personas (fides qua). Es el anhelo y búsqueda de la certeza en materia de fe, según lo señala Newman (1992: 193):

Pero si la religión ha de consistir en verdadera devoción y no ha de ser un mero sentimentalismo, si ha de constituir el principio supremo de nuestra vida [...] necesitamos más que un cierto contrapeso de argumentos para fijar y controlar nuestro espíritu. El sacrificio de las riquezas de la fama, de la posición, la fe y la esperanza, el dominio de sí mismo [...] presuponen una 
aprehensión real y una intuición habitual de los objetos de la revelación, que no puede tener otro nombre que certeza.

Con este interés es posible entonces adentrarse en la estructura propia del análisis gramatical de Newman ${ }^{9}$, cuestión que se desarrolla en el apartado siguiente.

\section{LA GRAMÁTICA CONCEPTUAL EPISTEMOLÓGICA}

"Nuestra religión nacional profesa ser poco más que leer la Biblia y el vivir una vida correcta. No es una religión de personas y cosas, de actos de fe y de devoción directa sino de escenas sagradas (sacred scenes) y de sentimientos piadosos. Relativamente ha descuidado el credo y el catecismo" (Newman, 1992: 58). Epistemológicamente hablando, Newman criticaba la fe de su país que define como un tipo de fe nocional, conceptual, que se mueve en el ámbito de lo lógico formal. Esto le lleva a desarrollar en la Grammar of Assent las claves gramaticales que a su juicio estructuran el conocimiento humano y por tanto permiten reconocer a posteriori una fe real, a saber: La proposición; la aprehensión y la inferencia, se trataba de proponer, en definitiva, una gramática del asentimiento.

\subsection{La proposición}

El autor va desarrollando categorías lógico-formales que le permitan dar cuenta del cómo llevar adelante su estructura epistemológica. Sin embargo, esto le resulta chocante con su tradición empirista, se diría que solo atiende a ella en virtud de un avance progresivo hacia lo que quiere demostrar $^{10}$. En este sentido la proposición, pasa a ser el concepto inicial. En la medida que se clarifica tal concepto y se da cuenta de su estructura, se hace a la vez posible proyectarlo y ratificarlo.

La afirmación más elemental respecto de una proposición, afirma Newman, es que esta se compone de sujeto y predicado unidos por una cópula

9 Una de las principales claves investigativas en torno al pensamiento del cardenal Newman dice relación, precisamente, con su análisis gramatical. Ello se puede descubrir por la gran variedad de artículos y trabajos de tesis orientados a analizar tal estructura. Es un trabajo íntegro en esta perspectiva el realizado por Casey, (1984), material que puede resultar irrenunciable a la hora de iniciar una profundización en tal análisis. También puede ser productivo consultar: Aveling (1905), Briodckel (1918), Cazes (1960), Chenk (1986), Chiochetti (1948), Ciller (1950), Colby (1953), Ker (1977), (Klocker, 1965).

10 "His view on intellectual abstraction is incompatible with any form of empiricism" (Richardson, 2007: 40). 
(verbo). No obstante, la proposición puede tener distintas acepciones ${ }^{11}$ : Interrogativa, condicionada y categórica. Por ejemplo:

- Interrogativa: ¿Es la fe un don de Dios al hombre?

- Condicionada: En consecuencia, la fe es un don de Dios al hombre. - Categórica: La fe es un don de Dios al hombre.

El oxoniense sigue aquí la lógica clásica mostrando las diversas formas de enunciar proposiciones. Las tres acepciones citadas son distintas entre sí; en efecto, con estas tres formas de construir proposiciones se presentan distinciones, no obstante, entre ellas se exijan correlatos.

Una pregunta es algo distinto que una conclusión, como un asentimiento es distinto de una pregunta, pues nadie negará que una pregunta se distingue de una conclusión o de una afirmación; asimismo un aserto no es lo mismo que una conclusión - si bien existen condicionantes entre estas diversas proposiciones- podemos afirmar una cosa a uno, concluirla con otro, preguntarla a un tercero. Sin embargo, al afirmar no concluimos, y al afirmar no preguntamos (Newman, 1992).

En este contexto, las distintas proposiciones o diversos modos de enunciar proposiciones se analogan a las maneras de mantener las mismas proposiciones. Así una proposición interrogativa evidencia la duda mental; una proposición condicionada hará alusión a la inferencia; y la proposición categórica evoca el asentimiento ${ }^{12}$. Ahora bien, estos actos mentales no se entienden en Newman como meras conjeturas intelectuales, sino que forman parte de la naturaleza humana tal y cual es, por lo que "al ejercitarlos, no violamos las leyes de nuestra naturaleza - como sucedería con actos procedentes de extravagancia o debilidad-, sino que son actos conformes con la naturaleza y según la constitución genuina de la misma" (Newman, 1992: 27).

Aunque el autor desarrolla bastante los correlatos de tales proposiciones, no es su intención exponerlos a cabalidad; lo que persigue fundamentalmente es ocuparse de las proposiciones categóricas, cuyo ejercicio natural se expresa a través del asentimiento. Las otras proposiciones (entiéndase la duda y la inferencia) tendrán su lugar en el discurso newmaniano que aquí se sitúa, en la medida que digan relación con el asentimiento.

11 Para descubrir en síntesis las ideas newmanianas sobre tales acepciones, se propone consultar Darvil (1946).

12 Estas distinciones van posibilitando que el autor desarrolle su propia epistemología. Sus ideas, no obstante, se ven en este punto influidas por el teólogo anglicano J. Butler, Obispo de Durham. Newman reconoce elementos válidos para plantear correctamente la epistemología de la fe (Morado, 2000). 


\subsection{La aprehensión}

El análisis newmaniano se centra ahora en comprender cómo se desarrolla la proposición bajo el modo de asentimiento, y cuál es el lugar que el ejercicio de asentir solicita de parte de la aprehensión. En efecto, la pregunta ahora versa por el modo de aprehender una proposición a lo que Newman responderá: "aprehender una proposición es imponer un sentido a los términos que la componen" (Newman, 1992: 29). Evidentemente que siguiendo el concepto de proposición los términos que componen la misma son el sujeto y el predicado unidos por la cópula. Estos términos que componen la proposición pueden representar realidades experienciales fruto del acontecer externo, como también realidades abstractas. Por ejemplo, la afirmación el triángulo tiene tres lados pertenece a una categoría abstracta, pues tanto el sujeto como el predicado es abstracto y a este tipo de proposiciones Newman las llama nocionales, por ende, la aprehensión que de esta proposición se tenga será también nocional. "Hay proposiciones en las cuales uno o ambos términos son nombres comunes que representan algo abstracto [...] A estas proposiciones yo las llamo nocionales y a la aprehensión por la que las inferimos o asentimos a ellas las llamo aprehensión nocional" (Newman, 1992:29).

Por su parte, también existen las proposiciones reales, aquellas que, como se decía, son fruto de una experiencia o de una información externa al individuo, por ejemplo: El agua del mar es salada. En este caso tal afirmación se origina, bien en una experiencia personal con el agua del mar o en alguna información recibida respecto de tal proposición; ésta al verse confrontada con una experiencia de la misma se torna real. A este tipo de proposiciones Newman las llama reales y se asiente a ellas a través de una aprehensión real. "Hay otras proposiciones compuestas de nombres singulares, cuyos términos representan realidades únicas e individuales [...] A esas yo las llamo proposiciones reales y a la aprehensión de las mismas aprehensión real" (Newman, 1960: 43-44).

Esta distinción de proposiciones no dice relación única y exclusivamente con la materia de sus contenidos, sino que también dependerá del uso que de la proposición se tenga. Así, una proposición originalmente abstracta como la citada puede transformarse en aprehensión real dada una experiencia concreta de la misma, o que solicite de ella. Si se dice esta mesa tiene una superficie triangularporque tiene tres lados se está aludiendo a ideas abstractas en una experiencia de visión concreta. A falta de experiencia se queda sólo con la abstracción, pero dada la experiencia, lo abstracto se puede transformar en un modo de aprehensión real. Pasará así a ser una proposición real cuando las partes sean aprehendidas comprendiendo 
aquello a lo que remiten. En todo caso "la aprehensión real es más fuerte que la nocional” (Newman, 1992: 31).

Ambos modos de aprehensión —nocional, real-, no se oponen entre sí. No se deben entender en oposición o contradicción. Una proposición, explica Newman (1992), puede expresar a la vez en una misma mente lo que es nocional y lo que es real, como el caso que se acaba de citar de la mesa u otro que presenta el mismo Newman: Varium et mutabile semper femina. Aquí Virgilio expresa una verdad que él considera general (nocional), y al mismo tiempo la aplica al caso de Dido (real).

En estas definiciones no se puede excluir a aquel que tiene la experiencia o capta las proposiciones, pues de él depende el sentido de las mismas. De este modo, podría darse que un individuo aprehenda nocionalmente algo que otro aprehende realmente, la diferencia estará marcada por la experiencia de uno y otro. Incluso podría darse que una misma proposición pudiese ser captada nocionalmente o realmente por el mismo sujeto. Así al decir el aquicar es dulce puede ser entendida como una afirmación genérica o aplicada al terrón que se tiene en la boca y a la sensación gustativa que en ella se está produciendo. Así, comienza a distinguirse aquello que en clave de investigación resulta importante: La distinción epistemológica que deriva de un tipo de conocimiento nocional o real según sea el caso. Se verán un par de conceptos más en la descripción que plantea el autor.

\subsection{La inferencia}

La inferencia es un acto condicional porque la conclusión depende de la validez de las premisas. La condicionalidad muestra en qué se basa la inferencia: en la dependencia de la conclusión respecto a las premisas y en el fundamento de las premisas. Es decir, existe una necesidad de aprehensión previa. Respecto de la aprehensión, la propia comprensión de la inferencia adelanta su característica: "no podemos asentir a una proposición sin aprehenderla de alguna manera con la inteligencia; mientras que para inferirla no es necesario que la entendamos en su totalidad" (Newman, 1992: 28).

Parafraseando a Newman y en términos lógicos se diría que no se puede asentir la proposición $X$ es $Z$, hasta que se sepa algo sobre uno u otro de sus términos; pero se puede inferir que, si $X$ es $Y$, y además $Y$ es $Z, X$ ha de ser $Z$, tanto si se conoce o no se conoce el significado de $X$ y $Z$. En este sentido se puede afirmar que la validez de la inferencia se halla fuera de sí misma (está en las premisas), mientras que el asentimiento es, de algún modo, un acto que se fundamenta en sí mismo, esto porque la aprehensión no es sino un momento interno del proceso que desemboca 
en el asentimiento y es concomitante a éste. Se tendría que preguntar entonces: ¿Acaso la inferencia no tiene relevancia con respecto al asentimiento? Por supuesto que sí. La inferencia tiene su propia legitimidad y no cabe aquí cuestionar su rol específico en cuanto constitutivo natural del pensamiento que se dan en los variados usos del mismo.

El raciocinio es el gran principio de orden en el pensar [...] Permite que los entendimientos independientes de muchos individuos, actuando mutuamente el uno sobre el otro, dirijan su fuerza común hacia un mismo objeto o una única cuestión [...] Aunque el raciocinio no nos lleva hasta alcanzar la verdad, al menos nos enseña en qué dirección se encuentra... [nos permite] conocer qué cosas son probables y cuáles no lo son, lo que se requiere para probar un punto determinado, lo que falta a una teoría ... una cierta argumentación que es simplemente condicional nos indicará dónde y cuándo se requieren observaciones o experimentos [...] Además los procesos lógicos son útiles en cuanto nos permiten acabar ciertos estadios de una investigación con rapidez y seguridad [...] (Newman,1992: 228).

Pese a las garantías que la inferencia da, aparecen al menos dos razones $-\mathrm{y}$ aquí se dice-, que hacen imposible que ella se pueda ocupar de lo real o concreto: por un lado, su imposibilidad de determinar principios; y por otro el no poder definir juicios últimos. En efecto, si se quiere inferir algo es necesario solicitar determinadas premisas y asumirlas como verdaderas quedando así condicionadas a este paso previo anterior. Si quisiéramos dar cuenta de la validez de la premisa se tendría que probar, lo que inmediatamente solicita otro paso previo que justifique la probación de la misma. Esto llevaría a una serie de premisas y validaciones de la misma que serían sucesivamente previas a aquella premisa que interesa. De este modo se estaría en un problema sin fin, pues cada premisa solicitaría elementos nuevos que harían más divergente y escurridizo el raciocinio. En palabras de Newman (1992a: 218): "líneas de argumentación más diversas, divergentes, numerosas".

De este modo, afirmando la posibilidad real de llegar a los primeros principios que la premisa en cuestión solicita, se podría descubrir la base última del conocimiento, o "los escondidos manantiales de todo conocimiento [...] en ellos y no en las demostraciones silogísticas está todo el problema de la consecución de la verdad" (Newman, 1992b:216). (Newman, 1960: 169; 176-184). El problema es que tales primeros principios resultan factibles y creíbles para unos, pero no para otros, y dado que se está a la base misma del conocimiento no existe otra posibilidad que la de optar por unos sobre los otros. No obstante, hay algo que aquí queda claro; estos primeros principios deben — para liberarse de su consecución 
ad infinitum-, salirse del plano lógico-formal. El problema es que "lo abstracto sólo puede llevar a lo abstracto. Pero nosotros necesitamos llegar a lo concreto en nuestro raciocinio. El margen entre las conclusiones abstractas de la ciencia y los hechos concretos que queremos averiguar reduce la fuerza del método inferencial desde el poder de la demostración a la mera determinación de lo probable" (Newman, 1992: 215).

Lo particular concreto tiene preeminencia sobre lo general abstracto, y esto es lo que se busca; lo particular concreto, el problema es que no se llega a él a través de inferencias formales, como ya se ha descrito. Se hace necesario entonces reconocer un tipo de conocimiento distinto al inferencial que sólo se queda en el plano lógico-formal. Habrá entonces que considerar un tipo de conocimiento (real) que justifique con certeza aquellas situaciones ordinarias de la vida y que constituyen su sentido y objeto cotidiano, una de ellas se puede reconocer en el ámbito de la fe.

Así las cosas, en la búsqueda de la verdad y para que ésta pueda ser alcanzada "necesitamos un organon más delicado, más sutil y más elástico que la argumentación verbal" (Newman, 1992: 217). Es aquí donde la inferencia no logra alcanzar el objeto de razón que posibilite certeza, menos aún en materia religiosa, pues:

$[\ldots]$ los procesos metódicos de la inferencia [...] no son más que instrumentos de nuestra mente y requieren [...] aquel raciocinio real y aquella imaginación presente que les da un sentido que trasciende la letra, y que, aunque obra a través de ellos, sin embargo llega a conclusiones que van mucho más lejos que ellos (Newman, 1992: 250).

En síntesis, se puede señalar que la inferencia tiene un valor formal que se hace necesario, pero no vital para los efectos de alcanzar certeza de aquello que de hecho se da. Es decir, en lo concreto se ve limitada, aunque permite razonar con tanto más fuerza cuanto más abstracta sea la cuestión que soliciten las premisas. En este sentido la inferencia formal no deja de ser en sí misma una abstracción en extremo. La vida real, por su parte, siempre interfiere en lo abstracto de un modo más potente, aunque aquello que nos dé atención sea tanto más abstracto, es decir, implícitamente, la formalidad de la inferencia pudiese resultar necesaria. En efecto, el raciocinio mental no actúa sustituyendo al verbal, sino complementándolo.

El ejercicio mental no resulta perfectamente puro, pues el contenido cualquiera de una determinada premisa afecta a otros elementos constitutivos del individuo que incide, en lo real, en la valoración y definición de los acontecimientos mismos, aunque no se explicite necesariamente en un caso particular. Cuando se da esto, la inferencia se ha encontrado con elementos de la realidad del individuo en particular, siendo así deja de ser 
meramente conceptual y pasa de una abstracción a la realidad concreta de una vida en particular:

[...] tal proceso de raciocinio es más o menos implícito y sin la directa y plena advertencia de la mente que lo ejerce [...] nuestra mente no es capaz de llevar a cabo un análisis completo de los motivos que la llevan a una conclusión particular, y está movida y determinada sólo por una prueba global, que es únicamente reconocida en su conjunto y no en sus partes constituyentes (Newman, 1992: 233).

En consecuencia, la asimilación inferencial que posibilita el conocimiento no dice relación directa con los conceptos mismos y las premisas inferenciales que se tengan, sino en cómo es comprendida por los diversos entendimientos. Esto resulta interesante, pues, en definitiva, en materias de realidades concretas se estaría aproximando a un elemento personal que en materia religiosa y en particular respecto a la comprensión de la fe cristiana no es desestimable. Pues permitiría afirmar que aquello que es propio de la fe es, precisamente, su carácter de don personal que no depende en absoluto de los silogismos o conjeturas lógicas que bajo determinadas abstracciones se concluyan. Se habla de un rol activo del sujeto que piensa y en el pensar concluye y asiente.

\subsection{El asentimiento}

Un elemento que ya ha aparecido en el discurso pero que necesariamente requiere de un cierto análisis es la comprensión newmaniana del asentimiento. Lo propio del asentimiento es para el autor su carácter incondicional (Newman, 1992); la inferencia, por su parte, es de por sí condicional ${ }^{13}$, pues depende de las premisas: "la inferencia es condicional, es la aceptación de una proposición, el Asentimiento es incondicional; el objeto de Asentimiento es una verdad, el objeto de Inferencia es la verdad como verosimilitud. El problema que se ha emprendido es determinar cómo se pasa de un acto condicional a uno incondicional" (Newman, 1992: 209).

13 Con esto la inferencia queda en un nivel inferior frente al discurso al que apunta el autor. Se insiste en que la reacción de Newman es contra una religión abstracta y sin pasión vital, contra una teología "escolástica y noética", a la búsqueda de una experiencia religiosa práctica y vívida. No pretende negar el valor de lo conceptual ni hacer ciega la experiencia vivida, pues sabe que no hay ni puede haber una línea divisoria entre ambos. (Torres Queiruga, 1991). 
Tales conjeturas newmanianas - expresadas aquí en términos generales-, pueden resultar razonables y aceptables, no obstante, parece que pudiesen causar cierta confusión. Está claro que un asentimiento requiere para su ejercicio de asentir un acto previo anterior que es inferencial. El problema es que la inferencia es por su propia naturaleza condicional a la aprehensión de sus premisas, por lo que las posibilidades de certeza en ella quedan absolutamente condicionadas. En un devenir lógico, entonces, el asentimiento también quedaría condicionado por aquello que se infiere previamente a él. Si esto quedara aquí, evidentemente, el autor estaría atrapado en la formalidad de su distinción; por ello como previendo el problema, Newman comienza a interactuar con John Locke.

Locke (1823) planteaba que existen diversos grados de asentimiento, pues estos tienen directa relación con la fuerza de las premisas, las que a su vez son las que posibilitan tal o cual asentimiento. Se evidencia así en Locke una distinción entre el aspecto práctico y el teórico. En el ámbito de lo teórico la probabilidad puede estar estrechamente cercana a la certeza, aunque se distingue de la certeza, al menos cualitativamente. No obstante, en la práctica pudiesen entremezclarse indistintamente. La preocupación newmaniana pretende reconocer lo infundado del planteamiento de John Locke que no reconoce una participación real del sujeto en el asentimiento y es precisamente este acto de asentir el que el autor rescata y contrapone al discurso de Locke ${ }^{14}$.

El oxoniense afirma que la propuesta de Locke queda en el plano de lo teórico, pues la realidad no es así y por tanto estas reflexiones resultan irreales. En efecto señala Newman que "cuando estos autores hablan de grados de asentimiento no pretenden definir la posición de la mente con respecto a la adopción de una conclusión dada, sino que pretenden determinar la relación que hay entre esta conclusión y sus premisas..." (Newman, 1992: 151). Hay que explicitar que, si bien la inferencia no resulta necesariamente determinante frente al acto de asentir, puede incidir como condicionante del asentimiento. Pues, aunque no lo determine to-

\footnotetext{
14 Según Locke el asentimiento dependería invariablemente de la inferencia, la cual, como se decía, tiene su concomitante directa en la realidad. El problema aquí para Newman es que el sujeto se torna pasivo, y el asentimiento que este da a cualquier información que in ere no aporta al conocimiento de la misma. El asentimiento sería aquí la consecuencia natural y formal del proceso inferencial. En esto radica el distanciamiento de Newman respecto de Locke, pues como dice Ward: "El acto de asentimiento a una nueva conclusión es un paso de nido tomado por la mente en respuesta a muchas influencias racionales, latentes además de conscientes, y no el mero reconocimiento pasivo[...] esta es quizá — hablando de Newman— su más novedosa y sutil contribución al problema" (Ward, 1912: 246).
} 
talmente, lo condiciona, ya que según sea el caso inferencial podrá fortalecer o desvirtuar el asentimiento dado. Se citan aquí algunas posibilidades de tipos de asentimiento.

Existen de hecho asentimientos que permanecen en el tiempo, aunque los actos inferenciales que llevaron a asentir ya no estén o se hayan olvidado. En sentido inverso existen asentimientos que no permanecen en la persona, aunque las razones que la llevaron a asentir aún estén. Asimismo, se tiene la presencia de asentimientos que nunca llegan a formar parte de la persona, aunque tenga todos los elementos formal-inferenciales que sugiere tal o cual asentimiento; como también se presentan asentimientos que ofrecen cierta certeza aparentemente, aunque no existan razones suficientes. Más allá de esta variedad de tipos de asentimiento se debe reconocer que para el autor existe asentimiento cuando hay aceptación absoluta y sin ningún tipo de condicionamientos a una proposición, pero esto solicita una aprehensión concomitante (Ker, 2009). De este modo el asentir implica conocer el sentido intrínseco de una proposición, lo que exige del acto mental, pues aquello que se debe conocer es el predicado de la proposición. Se aprehende una proposición cuando se aprehende su predicado. El asentimiento puede tomar así tres direcciones:

- Directo a una proposición.

- A la verdad de una proposición.

- Tanto a la verdad de la proposición como a los motivos que la hacen verdadera.

Todos estos casos presentan un mismo ejercicio mental y presentan una adhesión absoluta en cuanto asentimiento, pero la fuerza que cada uno de ellos tenga es variable. En efecto, asentir a la verdad de una proposición tanto como a los motivos que la hacen verdadera tiene una fuerza concomitante mucho mayor. En este sentido la aprehensión se relaciona con el modo de aprehender y no sólo es prerrequisito del asentimiento, sino que le confiere a éste una propiedad particular. Se está entonces en un estado distinto de la mera formalidad progresiva hacia un asentimiento, pareciese que aquí se sugiere un acto distinto por parte del individuo.

Se piensa, por ejemplo, en las variables humanas que pueden incidir a la hora de dar un determinado asentimiento: el prejuicio, la escala de valores, la flexibilidad ante nuevos datos, el error en el proceso inferencial, e incluso la voluntad misma del sujeto. En este sentido el asentimiento da origen a una serie de sucesos y antecedentes que tomados en su conjunto se transforman en dinámicas variables a la hora de asentir. Esto reafirma también la idea en Newman de que el asentimiento es más que un hecho formal y abstracto, pues todo indicaría que en definitiva será la voluntad 
misma del sujeto la que determinaría el asentimiento definitivo y no necesariamente la logicidad de determinadas conjeturas.

Dicho de otro modo, si bien el asentimiento tiene carácter de absoluto (unreserved), no todos son iguales en términos de tener la misma fuerza (strength). En último término la intensidad de un asentimiento estará, en clave newmaniana, estrechamente relacionada con el carácter real o nocional que éste presente (esto permite solicitar la aprehensión que le antecede) y es esto mismo lo que da cuenta de su incondicionalidad. El autor se detendrá bastante en el tema de las posibilidades y tipos de asentimiento, esto lo llevará a reconocer la amplitud y riqueza del acto mismo de asentir. En lo que respecta a este estudio sólo se quiere destacar lo que a juicio personal revela con mayor nitidez el problema, pues se está haciendo una reflexión en virtud del análisis epistemológico previo al acto de fe ${ }^{15}$.

\section{ENTRE NOCIONES Y REALIDADES}

En el camino hasta aquí recorrido se puede ya afirmar que partiendo de la distinción entre inferencia y asentimiento lo que se busca es llegar a la aprehensión, de la aprehensión al juicio o asentimiento para reconocer así lo conocido. A su vez, en la aprehensión, Newman formula y elabora la distinción nocional-real: de este modo la aprehensión de proposiciones como nociones sería el estado normal de la inferencia. Por su parte, el estado normal del asentimiento es la aprehensión de proposiciones como cosas. Si la aprehensión nocional es afín a la inferencia, la aprehensión real es el concomitante natural del asentimiento. En palabras de Newman (1992: 38):

Los términos de una proposición o representan cosas o no. Si las representan son términos singulares, porque todas las cosas existentes son singulares. Pero si no representan cosas han de representar nociones y han de ser tér-

15 Se ha querido profundizar parcialmente en el estatuto epistemológico que se circunscribe, al menos con explicita referencia a partir del siglo XIX, en el contexto del desarrollo de la teología fundamental. En efecto, para la Teología fundamental esto ha de ser un camino irrenunciable, así lo ha entendido el desarrollo teológico posterior al punto de evidenciar que en epistemología se ha encontrado, hoy por hoy, con un incontable número de publicaciones, como señala Lorizio "La discussione intorno allo statuto epistemologico della teologia fondamentale ha vissuto momenti di grande vivacità e con ittualità fra le diverse scuole e i rappresentanti dei diversi modelli" (Lorizio, Sabetta, Sguazzardo \& Zák, 2004: 412). También: "Per quanto concerne la problematica relativa allo statuto epistemologico di questo ambito disciplinare, la bibliogra a è immensa" (Lorizio, Sabetta, Sguazzardo \& Zák 2004: 376-430). 
minos comunes. Los términos singulares proceden de la experiencia; los comunes de la abstracción. Yo llamo a la aprehensión de los primeros aprehensión real, y a la de los segundos nocional.

Esta cita del oxoniense permite reconocer que algunas proposiciones pueden ser aprehendidas realmente por un sujeto y de forma nocional por otro, o a la vez nocional y realmente por la misma mente, lo que subraya la idea que estas dimensiones categoriales nocional-real, a modo de distinción epistemológica, no dicen relación con el concepto en sí, sino con el sujeto que la formula y asiente, ubicando nuevamente la discusión en el carácter personal del asentimiento mismo.

La aprehensión nocional que posibilita un asentimiento nocional permite por el ejercicio mismo de su nocionalidad abrir los conceptos y relacionarlos mutuamente, extendiendo el conocimiento. La aprehensión real es en este sentido más particular y profundo, en cuanto conserva en la mente su carácter propio identificado con la realidad. De modo análogo se pueden aplicar estas distinciones a la religión y la teología como lo hace Newman (1992: 122): "La religión se preocupa de lo real, y lo real es particular. La teología se ocupa de lo nocional, y lo nocional es general y sistemático". Aquí se muestra la permanente relación y vínculo entre lo nocional y lo real aplicado a eventuales vínculos respecto del quehacer teológico y religioso. Ambas perspectivas no renuncian entre sí, por el contrario, se solicitan como distinciones de un conocimiento completo.

Ahora bien, ¿cómo se podrían sintetizar las ideas aquí expresadas? El primer elemento es que existe una experiencia (E) que un primer individuo (A) aprehende, llámese a esta realidad captada X. La experiencia (E) puede ser aprehendida por otro individuo (B) pudiendo generar en él una imagen distinta $(\mathrm{Y})$ a la del individuo $\mathrm{A}$. Con ello se pueden suscitar también proposiciones distintas que en cada uno de los individuos (A-B) se harán coherentes y consecuentes con la realidad experiencial aprehendida (E). Estas aprehensiones pueden posibilitar un asentimiento a la realidad que enuncian, dada la experiencia que de ellas se ha alcanzado. Piénsese ahora en un tercer individuo (C) que sólo aprehende lo que le es formulado por $\mathrm{A}$ y $\mathrm{B}$, es decir, $\mathrm{X}$ e $\mathrm{Y}$. En este caso el individuo $\mathrm{C}$ no tiene experiencia de $\mathrm{E}$ salvo los antecedentes aportados por A y B. Lo que sucede en $\mathrm{C}$ tiene entonces solo dos posibilidades, o bien se presenta en $\mathrm{C}$ una noción $(\mathrm{N})$ de aquello que siendo real ha sido transmitido por A y B o, por razón de experiencias previas (EP), de imágenes mentales antecedentes, $C$ pueda concatenar estas imágenes permitiéndole asentir a la aprehensión de aquello que A y B a su vez aprehendieron. En un esquema: 


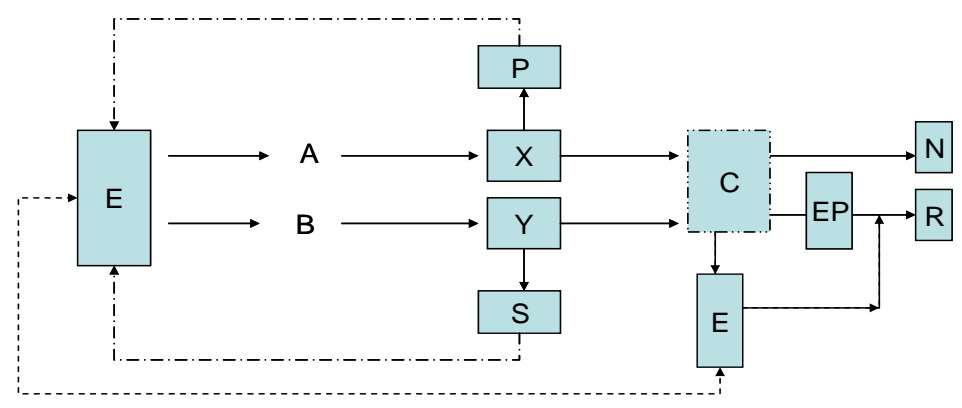

En cualquier caso, para que se diera un asentimiento real de $\mathrm{C}$ se requiere de la experiencia a priori a $\mathrm{X}$ e Y. Si no existen antecedentes previos, la noción aportada a $\mathrm{C}$ por $\mathrm{A}$ y $\mathrm{B}$ puede ser asentida pero sólo nocionalmente $(\mathrm{N})$. Para que $\mathrm{C}$ alcance un asentimiento real $(\mathrm{R})$ debe tener experiencia de $\mathrm{E}$ o asociar por imágenes de experiencias previas (EP) a $\mathrm{E}$ con sus propias imágenes mentales fruto de sus experiencias. Sea de modo directo o indirecto, la experiencia juega un rol determinante en el asentimiento real. La validez de las nociones solicita la experiencia, y a su vez la experiencia requiere de la noción para ampliar conocimiento. Lo nocional es sólo proposicional y lo real es experiencial. Por ello en el asentimiento nocional se asiente por uno u otro motivo a la verdad de la proposición, pero no a aquello que enuncia la proposición, es decir, en clave teológica; no hay asentimiento al Misterio de Dios mismo, sino al enunciado que se hace de él.

\section{CONCLUSIÓN}

Existe una distinción epistemológica que se describe y formula a lo largo de la Gramática del asentimiento. Y es esta misma distinción la que se observa subyacente a las posibilidades de la fe. La distinción epistemológica descrita permite afirmar que lo propiamente religioso en materia de fe es el objeto conocido o por conocer, pero el camino epistémico o medio a través del cual se llega a lo religioso termina siendo una forma común de alcanzar conocimiento. $Y$ es esta afirmación la que ahora vemos subyacente a las posibilidades de la fe como praeambula fidei, en este sentido reconocemos que la fe hace emerger algunas verdades que la razón ya tiene en su propia autonomía, abriéndonos paso hacia una teología fundamental. Así la metodología epistemológica es afín a todo tipo de conocimiento, también al religioso lo que sugiere la credibilidad del mismo acto de fe. 
Así sucede con el asentimiento, elemento propio del conocimiento humano que nuestro autor muestra y reivindica en su análisis, constituyéndolo parte del proceso cognitivo. Esto en cualquier área del conocimiento, digamos así, del conocimiento humano en general.

Lo nocional y lo real, si bien en sí mismos hablan de aspectos distintos de conocimiento, en el acto religioso en sí se condicionan mutuamente. Tal como se condiciona el asentimiento con la aprehensión que lo posibilita (Newman, 1992). La relación nocional-real fundamenta una epistemología que opera como distinción en la unidad. La distinción se erige al servicio de la relación. He aquí la potencialidad de la fe que permite confesarla y dar cuenta de su plausibilidad y razonabilidad al menos en sus preámbulos. Esto porque el ser humano, la persona toda, es más que pura racionalidad. La fe, por tanto, en cuanto acto humano, no exige de una fundamentación exclusivamente racional para dar cuenta de su razonabilidad.

Así la racionalidad —en cuanto epistemología- conduce a la posibilidad de alcanzar la fe religiosa, es decir, dar cuenta de la credibilidad de esta por la propia forma común que tiene el conocimiento racionalmente comprendido. En la base del asentimiento hay una dialéctica subconsciente. Es esta dialéctica la que engendra la certeza antes de la ciencia, y esta última desarrolla su rol esencial al poner y exponer aquel razonamiento espontáneo, técnicamente informal, pero humanamente válido. Así podemos concluir que:

El conocimiento de Dios es distinto al científico, abstracto y nocional.

El conocimiento real de Dios se realiza a través de los canales habituales para el asentimiento. Experiencia, afección, imagen, asentimiento.

En el acto del creer se evidencian los rasgos propios de la razón que permiten adquirir conocimiento a partir de fundamentos dados, y afirman una realidad porque existe otra que posibilita tal o cual afirmación.

Hablamos de la superación de los atributos racionales que no se condicionan a lógicas puramente formales.

No se exigen excepciones en la forma de conocer, sino que la diferencia radica en aquello que se conoce y la pretensión de un determinado conocimiento que podemos llamar religioso en razón del objeto, no del método, reorientando la ciencia y la fe como distintas formas de alcanzar conocimiento. Con todo, la Gramática del asentimiento explicita la autenticidad de la fe religiosa y su razonabilidad, que no apela a otro instrumento, sino al modo común en que el hombre adquiere conocimiento, asintiendo a lo que la imaginación le propone como objeto de fe. Esta prueba experiencial que requiere lo real, se transforma así en la base epistemológica que permite fundamentar a nuestro autor un momento previo, subyacente - a modo de praeambula - en el acto de fe, pasando de la racionalidad a la credibilidad. Con esto se revela en el discurso newmaniano de la Gramática 
del asentimiento, una propuesta epistemológica que se transforma en condición de posibilidad que encamina hacia la fe religiosa.

\section{REFERENCIAS}

-Antón, A. (1996). La "recepción” en la Iglesia y eclesiología (I): Sus fundamentos teológicos y procesos históricos en acción desde la epistemología teológica y eclesiología sistemática. Gregorianum, (77), 33-56.

-Aveling, F. (1905). Universals and the Illative Sense. Dublin: Review, (137), 236271.

-Briodckel, A. (1918). Cardinal Newman's Theory of Knowledge. American Catholic. Quarterly, (43), 508-604.

-Casey, G. (1984). Natural reason, A Study of the Notions of Inference, Assent, Intuition, and First Principles in the Philosophy of John Henry Newman. New York: Peter Lang Publishing, Inc.

-Cassirer, E. (2000). El problema del conocimiento. Madrid: Fondo de Cultura Económica.

-Cazes, M. (1960). La philosophie de la foi chez Newman. Victorian Studies (4), 99-117.

-Chenk, D. (1986). Newman's Complex Assent and Foundationalism. International Studies in Philosophy, (26), 229-240.

-Chiochetti, E. (1948). Il punto de partenza e il criterio della verità nella philosophia de Enrico Newman. Attualità Filosofiche (3), 236-400.

-Ciller, A. D. (1950). Newman and the Use of Knowledge. Journal of General Education, Chicago (s/n), 269-279.

-Colby, R. (1953). The Structure of Newman's Apologia pro vita sua in relation to his Theory of Assent. Dublin: Review, (117), 140-156.

-Congar, I. (1970). La fe y la teología. Barcelona: Herder.

-Copleston, F. (1969). Historia de la filosofía (vol. VIII). Barcelona: Ariel.

-Darvil, B. (1946). A preface to Newman's Theology. London: Herder Book Company.

-De Hipona, A. (1979). La verdad ontológica. De la verdadera religión. En F. Canals, Textos de los grandes filósofos. Edad media (cap. 39). Barcelona: Herder.

-Denzinger \& Hunerman (2002). El Magisterio de la Iglesia. Barcelona: Herder.

-Dessain, S. (1960). The Newman Archives and the Projected Edition of the Cardinal's Letters. Catholic Historical Review, 46(1), 22-26.

-Ferrater Mora, J. (2004). Diccionario de Filosofía. Barcelona: Ariel.

-Fisichella, R. \& Latourelle, R. (1992). Diccionario de Teología fundamental. Madrid: Paulinas.

-Fisichella, R. (1993). Introducción a la teología fundamental. Estella: Verbo Divino.

-Fuente Martínez, A. (1998). Revelación y fe en Henry Newman. Mayéutica, (58), 431-484.

-Heidegger, M. (2007). De la esencia de la verdad. Barcelona: Herder.

-Ker, I. (1977). Newman on Truth. The Irish Theological Quarterly (44), 67-68.

-Ker, I. (2009). John Henry Newman una biografía. Madrid: Palabra. 
-Kérn, W. \& Niemann, F. J. (1986). El conocimiento teológico. Barcelona: Herder. -Klocker, H. (1965). Newman and Causality. Heythrop Journal, (6), 160-170. -Llano, A. (1983). Gnoseología. Pamplona: Eunsa.

-Locke, J. (1823). An Essay concerning Human Understanding. The Epistle to the reader. London: Clarendon Edition.

-Lonergan, B. (1988;). Método en teología. Salamanca: Sígueme.

-Lorizio, G.; Sabetta, A.; Sguazzardo, P. \&Zák, L'. (2004). Teologia fondamentale, Epistemologia. Roma: Città Nuova.

-Morado, G. (2000). También nosotros creemos porque amamos, tres concepciones del acto de fe, Newman, Blondel, Garrigou-Lagrange. Estudio comparativo desde una teología fundamental. Roma: Editrice Pontificia Universitá Gregoriana.

-Newman, J. H. (1908). Apología pro vita sua. A History of His Religious Opinions. New York, Bombay and Calcuta: Longmans, Green \& co.

-Newman, J. H. (1960). Asentimiento religioso. Barcelona: Herder.

-Newman, J. H. (1962). The Letters and Diaries of John Henry Newman. S. Dessain, G. Tracey (Ed., Vol. XIX). Oxford: Clarendon Press.

-Newman, J. H. (1992). Grammar of Assent. USA: Notre Dame.

-Newman, J. H. (2003). Fifteen sermons preached before the University of Oxford between a.d. 1826 and 1843. USA: Notre Dame.

-Pannenberg, W. (1981). Teoría de la ciencia y teología. Madrid: Cristiandad.

-Pooper, K. (1974). Conocimiento objetivo. Madrid: Tecnos.

-Renic, D. (2015). Personal Narrative and Epistemology The Case of John Henry Newman. Revista de Filosofía, 47(139), 89-104.

-Richardson, L. (2007). Newman's Approach to knowledge. Reino Unido: Publishing Technology.

-Russell, B. (1978). Los problemas de la filosofía (Quinta edición). Barcelona: Labor.

-Rutler, G. (1990). El empirismo gramatical de Newman. Scripta theologica (22), 745-755.

-Tejedor, C. (1984). Filosofía. Madrid: SM.

-Torres Queiruga, A. (1991). Fe y razón en una época de crisis. Revista española de teología, (51), 5-42.

-Toulmin, S. (1976). Knowing and Acting, An invitation to philosophy. Nueva YorkLondres: Macmillan publishing Co., Inc.

-Ward, W. (1912). The life of John Henry Cardinal Newman. New York, London, Bombay and Calcuta: Longmans Green and co.

-Wartofsky, M. (1973). Introducción a la Filosofía de la ciencia. Madrid: Alianza.

Sumario: 1. Introducción: el decir epistemológico; 1.1. Conocimiento y verdad; 1.2. Otra forma de conocimiento; 2. La comprensión epistemológica de Newman; 2.1. El método newmaniano; 2.2. De la formalidad a la credibilidad; 2.3. De la imagen al conocimiento; 3. La gramática conceptual epistemológica; 3.1. La proposición; 3.2. La aprehensión; 3.3. La inferencia; 3.4. El asentimiento; 4. Entre nociones y realidades; Conclusión; Referencias. 